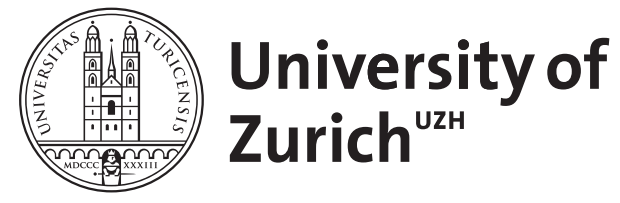
Archive

University of Zurich

University Library

Strickhofstrasse 39

CH-8057 Zurich

www.zora.uzh.ch

Year: 2021

\title{
Functional imaging of Bow Hunter's syndrome
}

Germans, Menno R ; Schweizer, Juliane ; Kulcsar, Zsolt

DOI: https://doi.org/10.1002/ana.26024

Posted at the Zurich Open Repository and Archive, University of Zurich

ZORA URL: https://doi.org/10.5167/uzh-197044

Journal Article

Accepted Version

Originally published at:

Germans, Menno R; Schweizer, Juliane; Kulcsar, Zsolt (2021). Functional imaging of Bow Hunter's syndrome. Annals of Neurology, 89(5):1051-1052.

DOI: https://doi.org/10.1002/ana.26024 


\title{
Functional imaging of Bow Hunter's syndrome
}

\author{
Menno R. Germans, MD, PhD \\ Department of neurosurgery \\ Clinical neuroscience center \\ University Hospital Zurich \\ Juliane Schweizer, MD \\ Department of neurology \\ Clinical neuroscience center \\ University Hospital Zurich \\ Zsolt Kulcsar, MD \\ Department of neuroradiology \\ Clinical neuroscience center \\ University Hospital Zurich
}

\author{
Corresponding author: Menno R. Germans, MD, PhD \\ Corresponding author's address: University Hospital Zurich, Frauenklinikstrasse 10, 8091 Zurich, SWITZERLAND \\ Corresponding author's phone and fax: +41 442553169 \\ Corresponding author's e-mail address: Menno.Germans@usz.ch
}

Running head: Bow Hunter's Syndrome

Acknowledgement statement (including conflict of interest and funding sources): all authors declare no conflict of interest.

This article has been accepted for publication and undergone full peer review but has not been through the copyediting, typesetting, pagination and proofreading process which may lead to differences between this version and the Version of Record. Please cite this article as doi: 10.1002/ana.26026 
To the Editor:

Drs. Jason Barton and Paul Ranalli in their recent publication "Vision Therapy: Ocular Motor Training in Mild Traumatic Brain Injury" put forward the premise that eye movement disorder is not the cause of symptoms experienced by persons with mTBI.1 In doing so, they discuss several papers from our laboratory, which they have misinterpreted.

Drs. Barton and Ranalli challenge the conclusions of research by Padula et. al. concerning Post Trauma Vision Syndrome (PTVS). 2 This research documents reduction in the amplitude of the visual evoked potential (VEP) P-10o pattern reversal for those with TBI (experimental group) compared to controls. Basein prisms affecting the spatial visual process produced an increase in amplitudes (experimental group) compared to the control thereby affecting oculomotor function. These conclusions are supported by research from C. Trevarthen, Liebowitz, Post and others, which is not discussed by Barton and Ranalli. 5 The conclusion by Padula et. al. is that TBI compromises visual processing producing a constellation of subjective symptoms and binocular characteristics of oculomotor dysfunction that they named PTVS. This conclusion actually agrees with Barton and Ranalli's premise rather than disagrees since it concludes that the "eye movement disorder" is not causative of the symptoms. Also, the research has nothing to do with "ocular motor training" as defined by Barton and Ranalli.

Drs. Barton and Ranalli then cite research by Padula et. al. about the "(Visual) Midline Shift Syndrome (VMSS)" without citing the two primary sources of the research.3,4 They incorrectly state that, "It (VMSS) refers to a deviation of the subjective estimate of midline" as a conscious subjective interpretation. Padula et. al. state in contrast, that visual midline functions preconsciously with proprioception to align the center of mass (COM) and maintain posture upright against gravity. Neither study by Padula et.al. incorporates any subjective interpretation of visual midline as alluded to by Barton and Ranalli. The studies demonstrate statistical significance for re-alignment the COM using yoked prisms to affect balance and postural alignment. Neither paper has anything to do with vision therapy or oculomotor training and Barton and Ranalli do not discuss the references included that support the conclusions. 3,4,5

Barton and Ranalli have mis-represented the conclusions of the Padula et.al. research that dysfunction of the visual process is the cause of related symptoms and binocular characteristics (not eye movements) and that visual processing dysfunction affects balance. They provide no evidence to disprove the research regarding PTVS and VMSS.

William V. Padula, OD

Padula Institute of Vision

Guilford, CT

\section{References}

1. Barton JS, Ranalli PJ. Vision Therapy: Ocular Motor Training in Mild Traumatic Brain Injury. ANN NEUROL 2020;00:1-9.

2. Padula WV, Argyris S, Ray J. Visual evoked potentials (VEP) evaluating treatment for post-trauma vision syndrome (PTVS) in patients with traumatic brain injuries (TBI). Brain Inj. 1994;8(2):125-33. 
3. Padula WV, Nelson CA, Padula WV, Benabib R, Yilmaz T, Krevisky S. Modifying postural adaptation following a CVA through prismatic shift of visuo-spatial egocenter. Brain Inj. 2009;23(6):566-76.

4. Padula WV, Subramanian $P$, Spurling $A$, Jenness J. Risk of fall (RoF) intervention by affecting visual egocenter through gait analysis and yoked prisms. Neuro-Rehabilitation. 2015;37(2):305-14.

5. Trevarthen CB. Two mechanisms of vision in primates. Psychol Forsch. 1968;31(4):299-348. 